\title{
SNP Genotyping by Multiplexed Solid-Phase Amplification and Fluorescent Minisequencing
}

\author{
Michael H. Shapero, ${ }^{1,2}$ Kerstin K. Leuther, ${ }^{1}$ Anhthu Nguyen, Melissa Scott, and \\ Keith W. Jones ${ }^{2,3}$ \\ Affymax Inc., Palo Alto, California 94304, USA
}

\begin{abstract}
The emerging role of single-nucleotide polymorphisms (SNPs) in clinical association and pharmacogenetic studies has created a need for high-throughput genotyping technologies. We describe a novel method for multiplexed genotyping of SNPs that employs PCR amplification on microspheres. Oligonucleotide PCR primers were designed for each polymorphic locus such that one of the primers contained a recognition site for Bbvl (a type IIS restriction enzyme), followed by 11 nucleotides of locus-specific sequence, which reside immediately upstream of the polymorphic site. Following amplification, this configuration allows for any SNP to be exposed by Bbvl digestion and interrogated via primer extension, four-color minisequencing. Primers containing $5^{\prime}$ acrylamide groups were attached covalently to the solid support through copolymerization into acrylamide beads. Highly multiplexed solid-phase amplification using human genomic DNA was demonstrated with 57 beads in a single reaction. Multiplexed amplification and minisequencing reactions using bead sets representing eight polymorphic loci were carried out with genomic DNA from eight individuals. Sixty-three of 64 genotypes were accurately determined by this method when compared to genotypes determined by restriction-enzyme digestion of PCR products. This method provides an accurate, robust approach toward multiplexed genotyping that may facilitate the use of SNPs in such diverse applications as pharmacogenetics and genome-wide association studies for complex genetic diseases.
\end{abstract}

The capability to discern genetic variation among individuals is fundamental to the further understanding of genetic predisposition to complex diseases such as cancer, mental illness, and diabetes. The multifactorial and heterogeneous nature of these complex diseases has highlighted the need for genetic association studies, as opposed to linkage mapping, as the preferred method to determine the underlying genetic cause of these diseases (Risch and Merikangas 1996; Gray et al. 2000; Schork et al. 2000). Coupled with this focus on genetic association studies has been the reemergence of singlenucleotide polymorphisms (SNPs) as the marker of choice in these types of studies based on their abundance, stability, and adaptability to automation (Kruglyak 1999). Major efforts in both the public (Human Genome Project) as well as the private (The SNP Consortium) sectors are underway to generate high-density, evenly spaced SNP maps, the first of which has recently been published (Sachidanandam et al. 2001). These polymorphisms, and the maps derived from them, will provide the framework for powerful new studies to identify genes involved in the pathophysiology of polygenic diseases, as well as diagnostic markers and predictors of differential drug response. Clearly, the wide-ranging applications of SNPs in pharmacogenetics and clinical association studies will necessitate further development of robust, flexible, cost-effective technology platforms for scoring genotypes in large numbers of samples.

'These authors contributed equally to this work.

2Present address: Affymetrix Inc., 3380 Central Expressway, Santa Clara, CA 95051.

${ }^{3}$ Corresponding author.

E-MAIL keith_jones@affymetrix.com; FAX (408) 481-0435.

Article published on-line before print: Genome Res., 10.1101/gr. 205001. Article and publication are at http://www.genome.org/cgi/doi/10.1101/ gr.205001.
A variety of schemes useful in the molecular genotyping of SNPs have been described over the years (for review, see Landegren et al. 1998 and Shi 2001) including those that discriminate alleles via hybridization (allele-specific PCR [Liu et al. 1997], DNA microarrays [Wang et al. 1998], Taqman [Livak 1999]) and those that discriminate alleles via enzymatic means (RFLP [Kan and Dozy 1978], oligonucleotide ligation assay [OLA; Grossman et al. 1994; Iannone et al. 2000], singlebase chain extension [Pastinen et al. 1997; Cai et al. 2000] and pyrosequencing [Alderborn et al. 2000]). These methods offer the capability of accurate genotyping, but they all rely on standard PCR amplification of target sequences as the initial front-end step in generating material. Because of the technically demanding nature of standard solution-based multiplexed PCR, which often can require extensive optimization of primers and reaction conditions (Edwards and Gibbs 1994), the inherent amplification requirement effectively limits the extent to which these varied platforms can be modified for highly multiplexed genotyping. The ability to convert hundreds of PCR primer-pairs into a single-tube, multiplexed reaction producing specific, robust products from a complex genomic DNA template would greatly reduce the requirements for large-scale, population-based SNP genotyping.

In this report, we describe a novel SNP genotyping platform that combines PCR amplification and four-color minisequencing (Pastinen et al. 1997) on acrylamide microspheres, with fragment detection and analysis using an automated sequencer. This system is capable of highly multiplexed PCR in a single reaction tube, as demonstrated by the simultaneous amplification of 57 human genetic loci. Multiplexed PCR and four-color minisequencing with eight individuals were carried out using bead sets representing eight polymorphic loci. 63 of the 64 genotypes were accurately determined with this approach. This system combines the sen- 
sitivity of PCR and a universal fluorescent read-out step with the capability of high multiplexing, creating an accurate, robust approach to SNP genotyping.

\section{RESULTS}

\section{Solid-Phase PCR from Human Genomic DNA}

Figure $1 \mathrm{~A}$ is a schematic diagram illustrating solid-phase PCR. During the first cycle, denatured target DNA anneals to primers that are covalently bound on their $5^{\prime}$ ends to beads. Primers are extended on their free 3' $\mathrm{OH}$ ends during the extension phase. During the second PCR cycle, covalently bound primer extension products hybridize to complementary primers that reside in close proximity on the bead surface. After the second extension cycle, double-stranded PCR product is covalently bound to the beads at both of its 5' ends. During the third and all subsequent denaturation, annealing, and extension cycles, additional PCR product is generated on the solid phase until primers are consumed. High concentrations of localized primers, coupled with the lack of solution-phase primers, provide each template with a minimal-complexity oligonucleotide probe set and decreases the likelihood of nonspecific priming and product cross-reactivity that normally can occur during multiplexed amplification.

Solid-phase amplification of preamplified DNA templates previously has been demonstrated (Adams and Kron 1997; Mitra and Church 1999). In an attempt to determine if solid-phase amplification using locus-specific primers was sensitive enough to amplify from genomic DNA, we polymerized Acrydite-containing primers (Rehman et al. 1999) for the insulin receptor (INSR) RsaI polymorphism into spots immobilized on an acrylamide derivatized polyester sheet. Both the forward and reverse primer contained a NotI restriction site $5^{\prime}$ to the locus-specific sequence as a means to release the amplification product from the support (Fig. 1B). Following amplification and digestion with NotI, the correct size fragment was seen using as little as $8 \mathrm{ng} / \mu \mathrm{L}$ of sheared human genomic DNA. Furthermore, the removal of the genomic DNA template after a target hybridization step, but prior to amplification, indicates that the product is a result of amplification on the solid phase (data not shown). The PCR process can be described by the equation $\mathrm{N}=\mathrm{N}_{\mathrm{O}}(1+\mathrm{E})^{\mathrm{n}}$, where $\mathrm{E}$ defines the amplification efficiency, $\mathrm{N}_{0}$ is the initial number of target molecules, and $\mathrm{N}$ is the amount of product synthesized. Amplification reactions at early and intermediate cycle numbers were used to determine that the efficiency of solidphase PCR was near 0.3 (data not shown), whereas typical solution-phase amplification generally has an efficiency of 0.8 . Additionally, the effect of primer concentration on solidphase product yield also has been examined. No product is detected when the primer concentration is $1.0 \mu \mathrm{M}$. Product is detectable at a primer concentration of $10 \mu \mathrm{M}$, but increases with $100 \mu \mathrm{M}$ primer concentration. These results are in general agreement with calculations that at $100 \mu \mathrm{M}$ primer concentration, there is one primer molecule per $10 \AA$ on or at the bead surface. Thus, at $1 \mu \mathrm{M}$ primer concentration, the spacing of primers ( 1 primer per $1000 \AA$ ) can no longer support formation of a solid-phase product of average length, which is $250 \mathrm{bp}$.

\section{Multiplexed, Solid-Phase PCR}

To evaluate if solid-phase PCR could be multiplexed, we per- formed a single PCR reaction containing 57 1.0 $\mu \mathrm{L}$ acrylamide beads representing 53 different genes from 16 chromosomes. The primer sequences were obtained from the Genome Database (www.gdb.org) and were not chosen or optimized for their ability to enable solid- or solution-phase amplification. The primers also contained unique restriction sites for NotI that allow product release following amplification. The reaction products range in size from $\sim 70 \mathrm{bp}$ to $1300 \mathrm{bp}$. Following amplification en masse, the beads were digested individually with NotI, and supernatants were loaded onto acrylamide gels. Because the beads cannot be readily deconvoluted prior to digestion of product, the gel contains a random order of amplification products (Fig. 1C). Fifty-three of the 57 loci exhibit a predominant amplification product. We also have demonstrated multiplexing of up to 102 beads (17 distinct amplicons each represented six times, data not shown), which confirmed the reproducibility of product yield and purity of each amplification product.

\section{A}

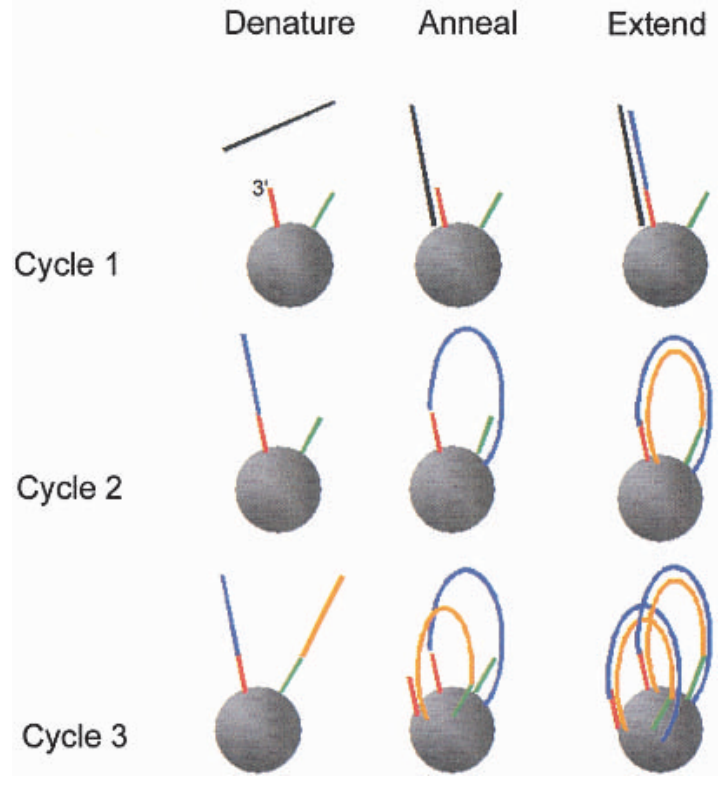

B

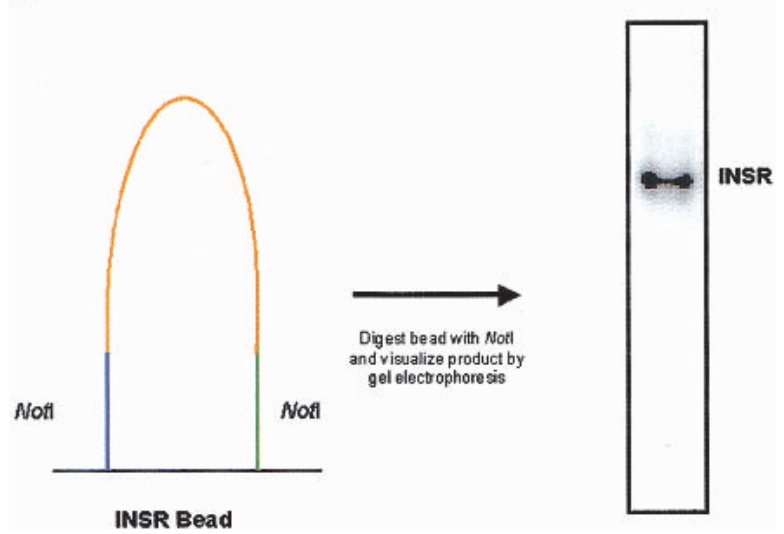

Figure 1 (Continues). 


\section{Single-Color SNP Minisequencing}

There are several general features of the primer design used for solid-phase amplification and genotyping. Each primer pair designed for a specific polymorphic locus contained the locus-specific sequence and introduced a $B b v \mathrm{I}$, a $S t u \mathrm{I}$ site, and a $P v u I I$ restriction site into the resulting PCR product. Figure $2 \mathrm{~A}$ illustrates the primers used to amplify the T102C polymorphism in the gene for human 5-hydroxytryptamine type $2 \mathrm{a}$ $\left(5-\mathrm{HT}_{2 \mathrm{a}}\right)$ receptor (Warren et al. 1993) and the product expected following amplification and digestion. The forward primer contains, after the $\mathrm{T}_{6}$ spacer and the StuI site, 15 bases of locus-specific sequence followed by the artificially introduced $B b v$ I site, and then 11 additional bases of locus-specific sequence at the $3^{\prime}$ end. The reverse primer contains 28 bases of locus-specific sequence following the $\mathrm{T}_{6}$ spacer and $P v u \mathrm{II}$ site. The purpose of the Type IIS $B b v$ I restriction site, which is precisely positioned 11 bases $5^{\prime}$ to the base with genetic variation, is to expose the polymorphic site upon digestion. The $S t u I$ site (always positioned on the same primer as the $B b v \mathrm{I}$ site) is used to remove one of the $B b v$ I-generated 5' overhangs and ensure that each bead utilizes only the $5^{\prime}$ overhang containing the polymorphic site immediately adjacent to the $3^{\prime}$ hydroxyl group of the recessed nucleotide as a template for ddNTP incorporation. PvuII digestion releases the amplification product after ddNTP incorporation.

To assess the specificity of the genotyping scheme, a model $135 \mathrm{bp}$ amplicon containing the $5-\mathrm{HT}_{2 \mathrm{a}} \mathrm{T} 102 \mathrm{C}$ polymorphism was evaluated using a single-color SNP minisequencing format. Individual beads containing a $5-\mathrm{HT}_{2 \mathrm{a}}$ primer pair were used for target hybridization and solid-phase amplification with genomic DNA template from a single individual who had previously been genotyped as a C/T heterozygote using a PCR-RFLP protocol (data not shown). Following $S t u \mathrm{I}$ and $B b v \mathrm{I}$ cleavage, beads were used in minisequencing reactions with individual FAM-ddNTPs (Fig. 2B). Fluorescent signal is observed only from the FAM-ddATP and FAM-ddGTP labeling reactions, corresponding to incorporation into the opposite strand of the C/T polymorphism. Sybr Green I staining of the gel after fluorescent imaging (Fig. 2C) shows that equal amounts of $5-\mathrm{HT}_{2 \mathrm{a}}$ PCR product were synthesized and released from each bead. The results show that $B b v \mathrm{I}$ can accurately cleave a solid-phase amplification product, which then can serve as a template for ddNTP incorporation.

\section{Four-Color SNP Minisequencing}

Single-color minisequencing reactions were converted to four-color minisequencing reactions by using a cocktail of all four ddNTPs that were individually labeled with distinct rhodamine dyes. Fluorescent-ddNTP incorporation reactions were carried out directly on bead-bound products. Fluorescent products were enzymatically released from beads, separated by denaturing gel electrophoresis, and data collection and analysis was via an automated sequencer with Genescan software. This platform therefore permitted quantitative detection of any color combination in an amplification product, including SNPs that are not biallelic. Figure 2D shows the four-color minisequencing of the $5 \mathrm{HT}_{2 \mathrm{~A}}$ locus amplified from the same heterozygous individual as used in Figure 2B. Incorporation of the rhodamine dye-labeled ddNTPs resulted in a gel image that was blue for R110-ddGTP, red for ROX-ddUTP, green for R6G-ddATP, and yellow for TAMRA-ddCTP. Near equal green and blue peaks, indicating a $\mathrm{C} / \mathrm{T}$ heterozygote, shows that the technique is able to accurately incorporate the correct base on a solid-phase template.

\section{Multiplexed, Solid-Phase Amplification and Four-Color SNP Minisequencing}

Multiplexing of the solid-phase amplification and minisequencing reactions was achieved by designing each released product to have a specific, discrete length. Thus, the length of the detected product identifies the polymorphic locus. Eight polymorphic loci were used to assess the accuracy of the multiplexed genotyping scheme. Bead sets for the eight polymorphic loci were used for target hybridization and multiplexed solid-phase amplification with genomic DNA from eight different individuals. A single reaction tube was used for each individual to genotype the eight loci. These individuals previously had been genotyped at each of the polymorphic loci by restriction enzyme digestion of PCR products or by direct DNA sequencing of PCR products. Following multiplexed solid-phase PCR, each bead set was used for four-color SNP minisequencing. Labeled products were released by PvuII digestion, and separated on a $6 \%, 8 \mathrm{M}$ urea acrylamide gel. A representative Genescan gel image is shown in Figure 3A. The eight displayed products for each individual span a range of sizes from $\sim 420 \mathrm{~b}$ (IL1B) to $\sim 110 \mathrm{~b}$ (CACNLG). Each of the

C

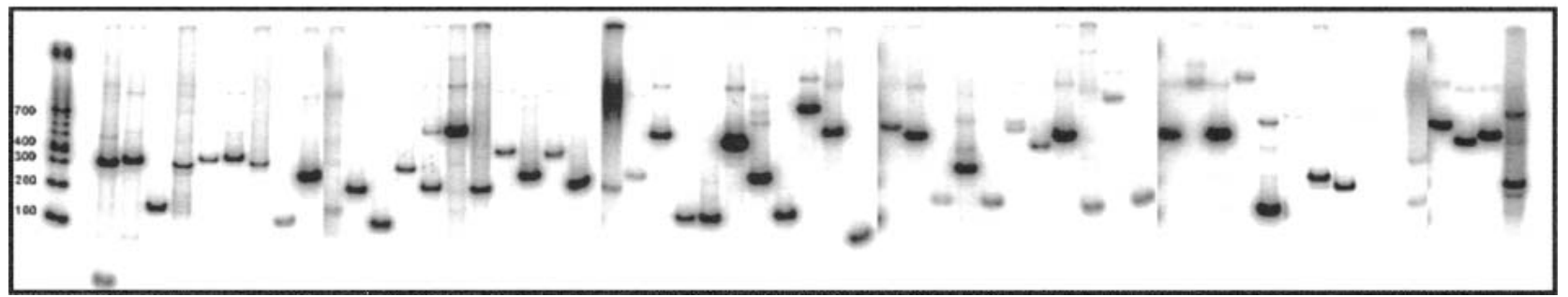

Figure 1 (A) Solid-phase amplification. Acrydite-containing primers are incorporated into an acrylamide bead or spot. Multiple cycles of denaturation, annealing, and extension result in a product that is covalently attached to the surface at both ends. (B) Solid-phase amplification from genomic DNA. Digested human genomic DNA was amplified using an acrylamide derivatized polyester sheet containing the INSR Rsal-specific primers. Amplification products were released from the beads with Notl and run on a 10\% acrylamide TBE gel. (C) Multiplex, solid-phase PCR with human genomic DNA. Shown is a composite of six $10 \%$ Acrylamide TBE gels. Fifty-eight beads ( 57 beads containing PCR primers and one blank bead) were multiplexed and the resulting radiolabeled products released from the beads are shown in random order. No amplification is observed with beads lacking oligonucleotide primers. Amplification products range in size from $\sim 70$ bp to $\sim 1300 \mathrm{bp}$. 


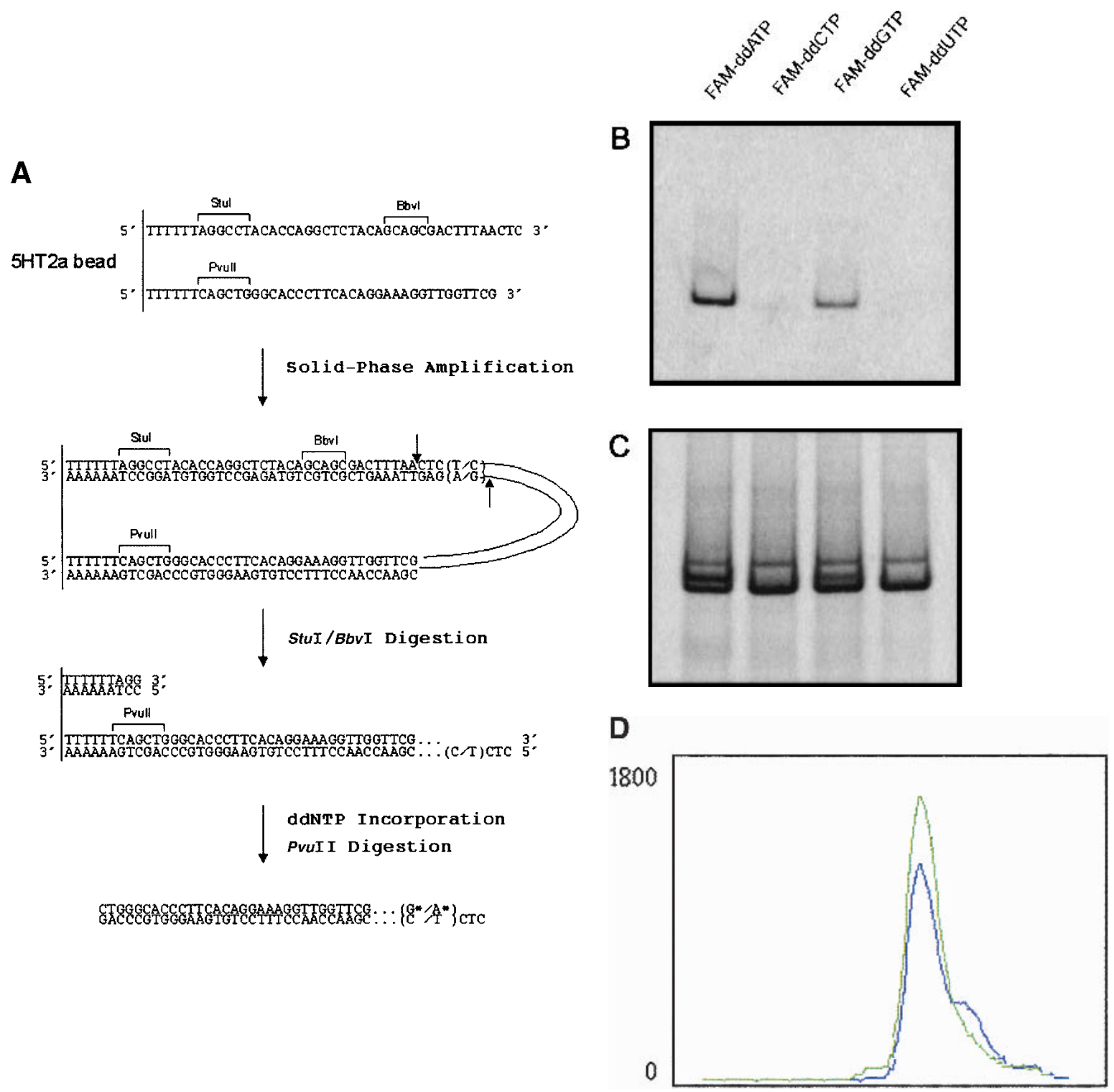

Figure 2 Single-nucleotide polymorphism (SNP) minisequencing. ( $A$ ) Diagram of the components and products of solid-phase amplification and SNP minisequencing using $5 \mathrm{HT}_{2 \mathrm{~A}}$-specific primers. The polymorphic site (C/T) is shown in parentheses. The fluorescently labeled nucleotides (G* or $A^{*}$ ) are depicted following $B b v l$ digestion and nucleotide incorporation. (B) Fluorescent image of $10 \%$ acrylamide gel with single-color FAM-ddNTP minisequencing of 5- $\mathrm{HT}_{2 \mathrm{~A}}$ solid-phase PCR product. (C) Sybr green I staining of same gel from panel $B$. (D) Four-color minisequencing of $5 \mathrm{HT}_{2 \mathrm{~A}}$ locus.

eight PCR products from the eight individuals was assigned a genotype after analysis of the electropherograms. Representative electropherograms for each genotype are shown in Figure 3B. Peak height ratios for the relevant colors were determined for all electropherograms. The results are summarized for each locus in Table 1. This collective data set shows that 63 of 64 genotypes determined by the multiplexed solid-phase amplification and four-color minisequencing method were accurately determined. The IL1B genotype for DNA sample No. 4 determined by AvaI enzyme digests was CC. When genotyped by the current method, this sample showed an elevated green peak ( $\mathrm{T}$ allele) that prevented a definitive genotype from being assigned. Whereas the peak height ratio was twofold higher than the CT heterozygote (DNA sample No. 3), it was not as high as the five additional CC homozygotes. Although peak height ratios differed between amplicons, they generally were consistent within a given locus.

\section{DISCUSSION}

We have enabled a high throughput genotyping platform that takes advantage of both the ability to simultaneously amplify multiple loci in a single reaction and the coupling of these reaction products to a generic minisequencing method that does not require additional locus-specific primers. The multiplexed amplification was carried out on a solid phase, thereby greatly reducing the local complexity of primers and eliminating artifactual priming events and primer-primer in- 
A

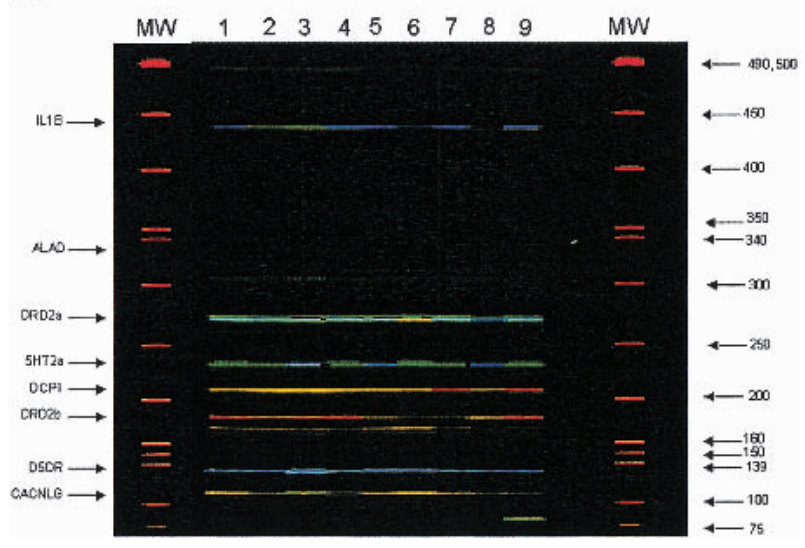

B

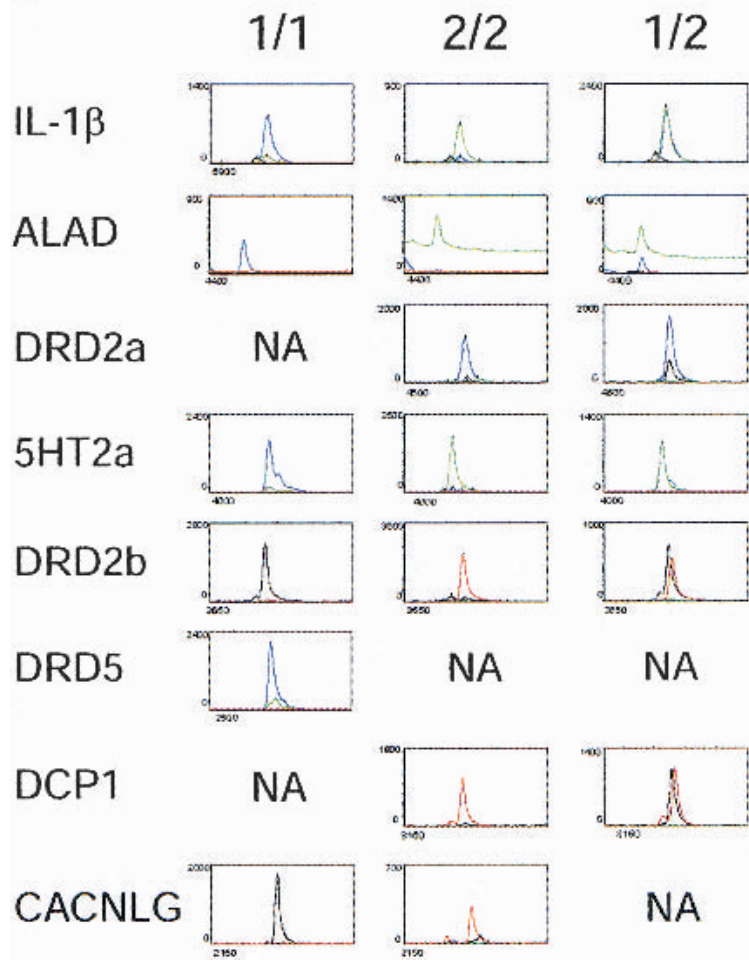

Figure 3 (A) An image of released solid-phase PCR/four-color minisequencing products separated on a $6 \%, 8 \mathrm{M}$ urea acrylamide gel. Lanes 1-8 contain products from eight unrelated individuals. Lane 9 is an internal reference standard, and lanes labeled MW contain the GENESCAN-500 ROX size standards. The identity of each amplified locus is shown on the left, and the sizes of the ROX-labeled standards are shown on the right. (B) Electropherograms for representative genotypes of each locus are shown. The $Y$ axis denotes relative fluorescent intensity, and the $X$ axis denotes scan number. The numerical genotype designations are indicated in Table 1.

teractions. Furthermore, one of the primers is designed such that digestion of the amplification product with a type IIS restriction enzyme will expose the site of polymorphism in a form that is directly amenable to interrogation via incorporation of a fluorescently labeled dideoxynucleotide. This methodology overcomes two critical bottlenecks faced in high-throughput genotyping; namely, the ability to perform highly multiplexed amplifications from genomic DNA and the ability to genotype multiple loci without having to add a complex mixture of primers.

It is widely held that PCR is the rate-limiting step in genome-wide analyses of sequence variation and that amplification efficiency, product specificity, and yield suffer when PCR amplifications are multiplexed (Edwards and Gibbs 1994; Landegren et al. 1998). Methods aimed at alleviating the requirement for amplification (Lizardi et al. 1998; Hall et al. 2000 ) or making the amplification of 100s-1000s of markers more efficient (Westin et al. 2000; Broude et al. 2001) have gained in popularity. The strength of our method stems from the ability to perform highly multiplexed amplifications from genomic DNA on acrylamide beads, thereby allowing us to combine the sensitivity of PCR with the capability to multiplex beads with distinct primer pairs in a single reaction. Because the primers remain immobilized to the bead surface through the $5^{\prime}$ end during amplification, PCR product is synthesized on the bead itself, thereby reducing the total primer complexity that would occur if primers were present free in solution. This minimizes the interactions between primers from different loci during multiplexed reactions, which can contribute to unwanted products such as primer-dimers or nonspecific amplification products.

Immobilization of the primers to the solid phase also allows for the removal of any unbound genomic DNA prior to the start of thermal cycling. Once prebinding of the target DNA to primers is complete, nonhybridized DNA is removed prior to the addition of enzymes for the extension and amplification reactions. This prevents production of solutionphase amplification products by trace amounts of primer that may leach from the beads during thermal cycling and minimizes formation of any artifactual products (mis-primed, primer dimers) commonly associated with multiplexed, solution-phase amplification. We have observed the maximum amount of product that can be generated on a $1-\mu \mathrm{L}$ bead via solid-phase amplification to be $\sim 100 \mathrm{ng}$. This yield is a function of multiple parameters including primer length, sequence composition, and surface density, which all function in concert to define an overall efficiency of solid-phase amplification. In addition, the sequence and length of the amplicon may affect the efficiency of the reaction, whereas the efficiency of amplification can range theoretically from zero to one, the value can vary experimentally from 0.46 to 0.99 for different genes in solution PCR (Chelly et al. 1988; Choi et al. 1989; Wang et al. 1998). Furthermore, the value has varied from 0.8 to 0.99 when the same gene was amplified in independent reactions under the same conditions (Wiesner 1992). We ascribe the decreased efficiency of solid-phase PCR (0.3) to the fact that the complementary DNA strands are held in close proximity to each other and can reanneal, thus decreasing the amount of DNA that can act as template in the next round of amplification. Experiments designed to shift the equilibrium away from reannealing of PCR product strands toward annealing of product strands to amplification primers (i.e., use of amplification primers with higher Tm and decreasing the amplicon length) are a means to increase the efficiency of solid-phase amplification.

The use of type IIS enzymes in genetic analysis has been described successfully in a variety of applications, such as gene expression analysis (Velculescu et al. 1995; Brenner et al. 2000) and mass spectrometry-based genotyping (Laken et al. 1998). The current method takes advantage of a type IIS re- 
Table 1. Genotype Scoring

\begin{tabular}{|c|c|c|c|c|c|c|c|c|c|}
\hline Locus & $\begin{array}{l}\text { Peak height } \\
\text { comparison } \\
\text { (Allele 1/Allele2) }\end{array}$ & DNA 1 & DNA 2 & DNA 3 & DNA 4 & DNA 5 & DNA 6 & DNA 7 & DNA 8 \\
\hline IL-1 $\beta$ & $\mathrm{C} / \mathrm{T}$ & $\begin{array}{c}\mathrm{CC} ; \mathrm{CC} \\
\mathbf{6 . 5}\end{array}$ & $\begin{array}{c}\mathrm{TT} ; \mathrm{TT} \\
\mathbf{0 . 2}\end{array}$ & $\begin{array}{c}\mathrm{CT} ; \mathrm{CT} \\
\mathbf{0 . 9}\end{array}$ & $\begin{array}{c}\mathrm{CC} ; \mathrm{CT} \\
1.8\end{array}$ & $\begin{array}{c}\mathrm{CC} ; \mathrm{CC} \\
7.3\end{array}$ & $\begin{array}{c}\mathrm{CC} ; \mathrm{CC} \\
10.1\end{array}$ & $\begin{array}{c}\mathrm{CC} ; \mathrm{CC} \\
11.4\end{array}$ & $\begin{array}{c}\text { CC;CC } \\
9.3\end{array}$ \\
\hline ALAD & $\mathrm{C} / \mathrm{T}$ & $\begin{array}{c}\mathrm{TT} ; \mathrm{TT} \\
\text { 0.1* }\end{array}$ & $\begin{array}{c}C C ; C C \\
\mathbf{2 2}^{*}\end{array}$ & $\begin{array}{c}\mathrm{CC} ; \mathrm{CC} \\
46^{*}\end{array}$ & $\begin{array}{l}\Pi ; \pi T \\
0.05^{*}\end{array}$ & $\begin{array}{l}\mathrm{TT} ; \mathrm{TT} \\
0.04^{*}\end{array}$ & $\begin{array}{c}\text { TC;TC } \\
\mathbf{0 . 6}\end{array}$ & $\begin{array}{l}\mathrm{TT} ; \pi T \\
0.04^{*}\end{array}$ & $\begin{array}{c}T \pi ; T T \\
0.1^{*}\end{array}$ \\
\hline DRD2a & $\mathrm{G} / \mathrm{C}$ & $\begin{array}{c}\text { GG;GG } \\
89^{*}\end{array}$ & $\begin{array}{c}\text { GG;GG } \\
90^{*}\end{array}$ & $\begin{array}{c}\text { GG;GG } \\
152^{*}\end{array}$ & $\begin{array}{c}\mathrm{GG} ; \mathrm{GG} \\
89^{*}\end{array}$ & $\begin{array}{c}\text { GG;GG } \\
\mathbf{8 . 0}\end{array}$ & $\begin{array}{c}\text { GG;GC } \\
\mathbf{3 . 0}\end{array}$ & $\begin{array}{c}\text { GG;GG } \\
115^{*}\end{array}$ & $\begin{array}{c}\text { GG;GG } \\
5.6\end{array}$ \\
\hline $5-\mathrm{HT} 2 \mathrm{a}$ & $\mathrm{T} / \mathrm{C}$ & $\begin{array}{c}\mathrm{TT} ; \mathrm{TT} \\
\mathbf{1 3 . 8}\end{array}$ & $\begin{array}{c}\mathrm{CT} ; \mathrm{CT} \\
1.5\end{array}$ & $\begin{array}{c}\mathrm{CC} ; \mathrm{CC} \\
0.3\end{array}$ & $\begin{array}{c}\pi ; \pi T \\
5.0\end{array}$ & $\begin{array}{c}\mathrm{CC} ; \mathrm{CC} \\
0.5\end{array}$ & $\begin{array}{c}\mathrm{TT} ; \mathrm{TT} \\
4.5\end{array}$ & $\begin{array}{c}\mathrm{CT} ; \mathrm{CT} \\
\mathbf{1 . 0}\end{array}$ & $\begin{array}{c}\text { CC;CC } \\
\mathbf{0 . 1}\end{array}$ \\
\hline DCP1 & $\mathrm{C} / \mathrm{T}$ & $\begin{array}{l}C C ; C C \\
\mathbf{1 1 3}^{*}\end{array}$ & $\begin{array}{c}\text { CC;CC } \\
170^{*}\end{array}$ & $\begin{array}{c}\mathrm{CC} ; \mathrm{CC} \\
131^{*}\end{array}$ & $\begin{array}{c}\mathrm{CC} ; \mathrm{CC} \\
120^{*}\end{array}$ & $\begin{array}{c}\mathrm{CC} ; \mathrm{CC} \\
133^{*}\end{array}$ & $\begin{array}{c}\mathrm{CC} ; \mathrm{CC} \\
118^{*}\end{array}$ & $\begin{array}{c}\mathrm{TT} ; \mathrm{TT} \\
\mathbf{0 . 1}\end{array}$ & $\begin{array}{c}C T ; C T \\
\mathbf{1 . 3}\end{array}$ \\
\hline DRD5 & $\mathrm{C} / \mathrm{T}$ & $\begin{array}{c}\mathrm{CC} ; \mathrm{CC} \\
3.2\end{array}$ & $\begin{array}{c}\mathrm{CC} ; \mathrm{CC} \\
3.4\end{array}$ & $\begin{array}{c}\mathrm{CC} ; \mathrm{CC} \\
3.5\end{array}$ & $\begin{array}{c}\mathrm{CC} ; \mathrm{CC} \\
5.6\end{array}$ & $\begin{array}{c}\mathrm{CC} ; \mathrm{CC} \\
\mathbf{6 . 1}\end{array}$ & $\begin{array}{c}\mathrm{CC} ; \mathrm{CC} \\
4.1\end{array}$ & $\begin{array}{c}\mathrm{CC} ; \mathrm{CC} \\
4.2\end{array}$ & $\begin{array}{c}\mathrm{CC} ; \mathrm{CC} \\
5.4\end{array}$ \\
\hline DRD2b & $\mathrm{T} / \mathrm{C}$ & $\begin{array}{c}\mathrm{TT} ; \mathrm{TT} \\
\mathbf{2 1 . 3}\end{array}$ & $\begin{array}{c}\mathrm{TT} ; \mathrm{TT} \\
39^{*}\end{array}$ & $\begin{array}{c}\mathrm{TT} ; \mathrm{TT} \\
21\end{array}$ & $\begin{array}{c}\mathrm{TT} ; \mathrm{TT} \\
18\end{array}$ & $\begin{array}{c}\mathrm{TC} ; \mathrm{TC} \\
0.8\end{array}$ & $\begin{array}{c}\text { TC;TC } \\
0.7\end{array}$ & $\begin{array}{c}\mathrm{TC} ; \mathrm{TC} \\
0.7\end{array}$ & $\begin{array}{c}\mathrm{TC} ; \mathrm{TC} \\
\mathbf{1 . 0}\end{array}$ \\
\hline CACNLG & $\mathrm{G} / \mathrm{A}$ & $\begin{array}{c}\text { GG;GG } \\
\text { 98* }^{*}\end{array}$ & $\begin{array}{c}\text { GG;GG } \\
31^{*}\end{array}$ & $\begin{array}{c}\text { GG;GG } \\
125^{*}\end{array}$ & $\begin{array}{c}\text { AA;AA } \\
0.2\end{array}$ & $\begin{array}{c}\text { GG;GG } \\
62^{*}\end{array}$ & $\begin{array}{c}\text { GG;GG } \\
102^{*}\end{array}$ & $\begin{array}{c}\text { GG;GG } \\
48^{*}\end{array}$ & $\begin{array}{c}\text { GG;GG } \\
19^{*}\end{array}$ \\
\hline
\end{tabular}

striction enzyme site positioned in one of the amplification primers, and digestion with the type IIS enzyme exposes the polymorphic site in such a way that it can be interrogated directly via fluorescent dye-labeled nucleotide incorporation. No additional synthesis of locus-specific oligonucleotides is required for the detection component of this genotyping system. This method not only utilizes the fidelity of the DNA polymerase in allele determination but also alleviates any need for separate genotyping probes and minimizes artifacts based on primer heterodimerization and false priming.

A potential drawback in this scheme is the requirement that the recognition site for the type IIS restriction enzyme is present only once in the amplification product and it is introduced via the primer. The impact of this requirement is minimized by having the freedom to choose which amplification primer (forward or reverse strand) will contain the type IIS recognition site and the need to amplify a minimum of one nucleotide, the polymorphic site. The requirement then is limited to only the nucleotides between the recognition site and the cut site (the "throw" of the enzyme). in the case of $B b v \mathrm{I}$, with a throw of 12 nucleotides, there are only nine opportunities for the GCAGC recognition site to appear, out of a total of $\sim 1.7 \times 10^{7}\left(4^{12}\right)$ different sequence combinations that can be present. Therefore, $<1$ in $2 \times 10^{6}$ polymorphisms will not be amenable to this method because a second $B b v \mathrm{I}$ site will be present in the amplification product. Another potential drawback in the current method is the use of gel electrophoresis as a means to deconvolute the multiplexed amplification products. Although this method has proved useful in genotyping of SNPs via minisequencing (Krook et al. 1992;
Pastinen et al. 1996) and OLA (Grossman et al. 1994), the number of loci that can be discriminated by size is well short of the theoretical capacity of the multiplexed amplification reaction. Several solutions exist that could be applied to the current method. First, solid-phase amplification could be performed on spatially addressable arrays rather than beads, as demonstrated by Westin et al. (2000). Second, it is conceivable to replace the product-release step with one in which the SNP genotype is read out directly on the bead itself. To this end, current efforts are underway to use an optical encoding scheme in which specific fluorophores distinct from the rhodamine dye-labeled ddNTPs are entrapped within the beads (Chen et al. 2000; Steemers et al. 2000). Lastly, incorporation of a unique DNA tag into the amplification product, followed by hybridization to a "tag array" containing spatially addressed sequences complimentary to each unique tag (Fan et al. 2000) will convert our solution phase, released products to a deconvoluted solid-phase array.

In conclusion, we have developed a high-throughput genotyping system that takes advantage of the ability to perform highly multiplexed amplification reactions on the solid phase and couples these products with a generic genotyping scheme that utilizes information contained within the amplification product and does not require additional nucleic-acid primers. The modular nature of this method should prove beneficial to existing methodologies that require either highly multiplexed amplification or the need for a generic, rapid readout. We believe the current method will prove useful as the number of SNPs and their use in genetic association studies increases. 
Table 2. Amplification Primers

\begin{tabular}{|c|c|c|}
\hline Primer & Oligonucleotide sequence & Reference \\
\hline IL1Bf & QTTTTTTAGGCCTTCAGAGGCTCCTGCCGCAGCCAGAGAGCTCC & di Giovine et al. 1992 \\
\hline $\mathrm{IL} 1 \mathrm{Br}$ & QTTTTTTCAGCTGGAATACCTGATTTCACAATCAAGTTAAAGG & \\
\hline ALADf & QTTTTTTAGGCCTTTCAACCCCTCTACCGCAGCCCACACAGGTA & Astrin et al. 1991 \\
\hline ALADr & QTTTTTTCAGCTGCCTCCCACCTCTCCACCTCCCGAGTAGC & \\
\hline DRD2af & QTTTTTTCAGCTGATGGAAATCACACAGTCACAAAGGAGCAGA & Hauge et al. 1991 \\
\hline DRD2ar & QTTTTTTAGGCCTTGGACTCACGAAGGCGCAGCCGGTGACCATT & \\
\hline 5-HT2Af & QTTTTTTAGGCCTACACCAGGCTCTACAGCAGCGACTTTAACTC & Warren et al. 1993 \\
\hline 5-HT2Ar & QTTTTTTCAGCTGGTTGGTGGCATTCTGCGGCTTTTTCTCTAG & \\
\hline DCP1f & QTTTTTTCAGCTGAGGGCCGCTCCCTCCTCATTCCTGTCTTTC & Rieder et al. 1999 \\
\hline DCP1r & QTTTTTTAGGCCTAGCCGGGGTTGGCCCGCAGCCGCAGGGAGAC & \\
\hline DRD5f & QTTTTTTAGGCCTACTGCATGGTCCCTTGCAGCAGTGGACACCC & Sommer et al. 1993 \\
\hline DRD5r & QTTTTTTCAGCTGGGCAAACACCTTCTGAAAGTCGGCGTTG & \\
\hline DRD2bf & QTTTTTTCAGCTGATAAGCATCAAGTGTTTGGAACAGTGCC & Hauge et al. 1991 \\
\hline DRD2br & QTTTTTTAGGCCTAGAGGAAGGAGTGGCGCAGCGTTCCCTAGTC & \\
\hline CACNLGf & QTTTTTTAGGCCTCTGTGCCGCCTTCATGCAGCTCTTTCTCGGC & Olckers et al. 1993 \\
\hline CACNLGr & QTTTTTTCAGCTGGAGGGTCGCTAGGGCCGCAGGAGGGTTA & \\
\hline
\end{tabular}

The sequence of the oligonucleotides $\left(5^{\prime}\right.$ to $\left.3^{\prime}\right)$ for each locus are shown with the $B b v l$ site (GCAGC) depicted in bold type, the Pvull site (CAGCTG) in italics, and the Stul site (AGGCCT) is underlined.

(Q) Designates the acrylamide group; (f) forward primer; $(r)$ reverse primer.
(TE containing $50 \mathrm{mM} \mathrm{NaCl}$ ), and twice in $1 \times$ GeneAmp PCR buffer prior to target hybridization.

\section{Target Hybridization and Solid-Phase Amplification}

For target hybridization, beads were incubated in $1 \times$ GeneAmp or $1 \times$ Taq Extender (Stratagene) buffer (20 mM Tris- $\mathrm{HCl} \mathrm{pH} 8.8,10 \mathrm{mM}$ $\mathrm{KCl}, 10 \mathrm{mM}\left[\mathrm{NH}_{4}\right]_{2} \mathrm{SO}_{4}, 2 \mathrm{mM}$ $\mathrm{MgSO}_{4}, 0.1 \%$ Triton X-100, $0.1 \mathrm{mg} /$ $\mathrm{mL}$ bovine serum albumin) containing 100-125 $\mathrm{ng} / \mu \mathrm{L}$ denatured, human genomic DNA that had been either sheared or digested with StuI. Target hybridization volumes were adjusted to just cover the beads $(10 \mu \mathrm{L}$ for a single $1-\mu \mathrm{L}$ bead, $80-100 \mu \mathrm{L}$ for $501-\mu \mathrm{L}$ or 100 $0.5-\mu \mathrm{L}$ beads). Beads were hybridized with human genomic DNA for 12-24 $\mathrm{h}$ in an Eppendorf thermomixer at $45^{\circ} \mathrm{C}$ and $850 \mathrm{rpm}$. After target hybridization, reactions were washed twice in STE, and twice in $1 \times$ Taq Extender buffer. Solidphase amplification reactions contained $1 \times$ Taq Extender buffer, 200 $\mu \mathrm{M}$ of each dNTP, 2.5U Amplitaq, 5U AmplitaqTaq Gold, and 5U Taq

\section{METHODS}

\section{Oligonucleotide Synthesis}

Oligonucleotides with a $5^{\prime}$ acrylamide group (Acrydite, Mosaic Technologies) (Rehman et al. 1999) were obtained from Operon Technologies, Inc. Lyophilized oligonucleotides were resuspended at a concentration of $1 \mathrm{mM}$ with $1 \mathrm{X}$ TE $(10 \mathrm{mM}$ Tris- $\mathrm{HCl}, \mathrm{pH}$ 8.0, $1 \mathrm{mM}$ EDTA) and were stored frozen at $-20^{\circ} \mathrm{C}$.

Each human locus that was analyzed is listed in Table 2 along with the Acrydite oligonucleotides used for solid-phase amplification.

\section{Preparation of Acrylamide Beads}

Gel solutions contained 10\% acrylamide (29:1 w/w acrylamide: bis-acrylamide), $10 \mathrm{mM}$ sodium borate buffer, $0.2 \%$ ammonium persulfate, and $100 \mu \mathrm{M}$ of each Acrydite primer. Nitrogen-saturated mineral oil containing 0.4\% TEMED (N, $\mathrm{N}, \mathrm{N}^{\prime}, \mathrm{N}^{\prime}$-tetramethylenediamine) was placed into a small polyethylene dish (weighboat), and 1.0 or $0.5 \mu \mathrm{L}$ aliquots of the gel solution were pipetted under the mineral oil. Beads were polymerized at room temperature for $1 \mathrm{~h}$. The mineral oil was decanted and the beads were recovered in TE. Beads were loaded into large wells of a $2 \%$ Agarose gel in $0.5 \times$ TBE, and unpolymerized primer was removed by electrophoresis at $130 \mathrm{~V}$ for $1 \mathrm{~h}$. Beads were removed from the wells with a large bore pipet tip and washed in TE. Beads were stored in TE at $4^{\circ} \mathrm{C}$ for up to $4 \mathrm{wk}$. Alternatively, acrylamide solutions containing Acrydite primers and both polymerization catalysts were spotted onto acrylamide-derivatized polyester sheets (GelBond PAG, FMC BioPolymer), and polymerized under nitrogen for a few minutes. Spots were treated to remove unpolymerized primer as described for beads.

Beads or spots were pre-cycled to decrease nonspecific amplification $\left(94^{\circ} \mathrm{C}\right.$ for $10 \mathrm{~min}$, then $94^{\circ} \mathrm{C}$ for $45 \mathrm{sec}, 45^{\circ} \mathrm{C}$ for $1 \mathrm{~min}, 72^{\circ} \mathrm{C}$ for $1 \mathrm{~min}$ for 15 cycles) in $1 \times$ GeneAmp PCR buffer (10 mM Tris-HCl, pH 8.3, $50 \mathrm{mM} \mathrm{KCl,} 1.5 \mathrm{mM} \mathrm{MgCl}_{2}$, $0.001 \%[\mathrm{w} / \mathrm{v}]$ gelatin) containing $0.25 \mathrm{ng} / \mathrm{\mu L}$ Escherichia coli genomic DNA (Sigma). Beads were washed three times in STE
Extender. In cases where PCR products were visualized directly, $1 \mu \mathrm{L}(10 \mu \mathrm{Ci})$ of ${ }^{32} \mathrm{P}-\alpha$-dCTP $(3000 \mathrm{Ci} / \mathrm{mmole})$ was also included. Reactions underwent an initial extension protocol $\left(60^{\circ} \mathrm{C}\right.$ for $5 \mathrm{~min}, 68^{\circ} \mathrm{C}$ for $5 \mathrm{~min}, 72^{\circ} \mathrm{C}$ for $\left.10 \mathrm{~min}\right)$ prior to cycling $\left(94^{\circ} \mathrm{C}\right.$ for $10 \mathrm{~min}$, then $94^{\circ} \mathrm{C}$ for $45 \mathrm{sec}, 65^{\circ} \mathrm{C}\left(-1^{\circ} \mathrm{C} /\right.$ cycle) for $1 \mathrm{~min}, 72^{\circ} \mathrm{C}$ for $1 \mathrm{~min}$ for 20 cycles, followed by $94^{\circ} \mathrm{C}$ for $45 \mathrm{sec}, 45^{\circ} \mathrm{C}$ for $1 \mathrm{~min}, 72^{\circ} \mathrm{C}$ for $1 \mathrm{~min}$ for 70 cycles). After cycling, beads were washed five times in STE.

\section{Release of ${ }^{32}$ P-Labeled, Solid-Phase PCR Product}

Single beads were manually recovered by using wide-bore pipette tips with a diameter greater than an individual bead. Beads were individually pipetted into tubes and incubated for $12-16 \mathrm{~h}$ in $10 \mu \mathrm{L}$ of solution containing appropriate restriction enzymes. Supernatants were loaded onto a 10\% Acrylamide TBE ( $89 \mathrm{mM}$ Tris-borate, $89 \mathrm{mM}$ boric acid, $2 \mathrm{mM}$ EDTA) gel and run at $200 \mathrm{~V}$ for $1 \mathrm{~h}$. Gels were dried and exposed to phosphoimaging cassettes for $1-3 \mathrm{~h}$. Screens were scanned with a Storm 860 instrument (Molecular Dynamics) at $200 \mu \mathrm{m}$ resolution.

\section{One-Color SNP Minisequencing}

Individual beads containing primers for a polymorphism in the human 5-hydroxytryptamine type $2 \mathrm{a}$ receptor $\left(5-\mathrm{HT}_{2 \mathrm{a}}\right)$ were used for solid-phase amplification. The primers were $5^{\prime}$ $\mathrm{QT}_{12}$ AGGCCTACACCAGGCTCTACAGCAGCGACTTTAACT$3^{\prime}$ and $5^{\prime}-\mathrm{QT}_{12}$ CAGCTGGGCACCCTTCACAGGAAAGG TTGGTTCG-3' where Q is the Acrydite group. After amplification, beads were equilibrated into $1 \times$ NEBuffer 2 (New England Biolabs; $50 \mathrm{mM} \mathrm{NaCl}, 10 \mathrm{mM}$ Tris- $\mathrm{HCl} \mathrm{pH} 7.9 @ 25^{\circ} \mathrm{C}$, $10 \mathrm{mM} \mathrm{MgCl}_{2}, 1 \mathrm{mM} \mathrm{DTT}$, and digested at $37^{\circ} \mathrm{C}$ for $16 \mathrm{~h}$ with 10 U StuI per bead. Beads then were rinsed with $1 \times$ NEBuffer 2 , and incubated for $4 \mathrm{~h}$ at $37^{\circ} \mathrm{C}$ with $1 \mathrm{U} \mathrm{BbvI}$ per bead. Beads were rinsed and equilibrated into $1 \times$ Amplitaq FS buffer for $10 \mathrm{~min}$ at room temperature. One-color sequencing reactions contained $1 \times$ Amplitaq FS buffer, $1.5 \mu \mathrm{M}$ of the single FAM (5-carboxyfluorescein)-labeled ddNTP (ddATP, ddCTP, ddGTP, or ddUTP) as well as $1.5 \mu \mathrm{M}$ of each of the three 
unlabeled ddNTPs. Reactions were incubated at $68^{\circ} \mathrm{C}$ for 30 min, and then beads were rinsed twice with TE buffer and unincorporated fluorescent ddNTP was removed by electrophoresis of the beads at $130 \mathrm{~V}$ for $1 \mathrm{~h}$. Beads were equilibrated into $1 \times$ NEBuffer 2 , and digested overnight at $37^{\circ} \mathrm{C}$ with $10 \mathrm{U}$ $P v u I I$ enzyme. Released products were analyzed by electrophoresis on $10 \%$ Acrylamide $1 \times$ TBE gels and run at $200 \mathrm{~V}$ for $1 \mathrm{~h}$. Gels were scanned with a Storm 860 instrument (blue fluorescence filter, PMT $900 \mathrm{~V}$ ) at $200 \mu \mathrm{m}$ resolution to detect the fluorescent signal. Gels then were stained with Sybr Green I (Molecular Probes) diluted 1:10,000 in 1× TBE for $30 \mathrm{~min}$ and reimaged using the same instrument setup to detect total released PCR product in all lanes.

\section{Four-Color SNP Sequencing}

Following solid-phase amplification reactions, beads were equilibrated into $1 \times$ NEBuffer 2 and digested overnight at $37^{\circ} \mathrm{C}$ with $40 \mathrm{U}$ StuI restriction enzyme. Beads were washed once with fresh $1 \times$ NEBuffer 2 , and then digested overnight at $37^{\circ} \mathrm{C}$ with $10 \mathrm{U}$ of the type IIS enzyme BbvI. Reactions then were equilibrated into $1 \times$ Amplitaq FS buffer. Four-color sequencing reactions $(100 \mu \mathrm{L})$ contained $1 \times$ Amplitaq FS buffer, $2 \mathrm{mM}$ manganese citrate, $1.5 \mu \mathrm{M}$ R6G-ddATP, $1.5 \mu \mathrm{M}$ R110-ddGTP, $1.5 \mu \mathrm{M}$ ROX (6-carboxy-X-rhodamine)-ddUTP, $1.5 \mu \mathrm{M}$ TAMRA $\left(\mathrm{N}, \mathrm{N}, \mathrm{N}^{\prime}, \mathrm{N}^{\prime}\right.$-tetramethyl-6-carboxyrhodamine)-ddCTP, and 5 U Amplitaq FS. All fluorescently labeled ddNTPs were from NEN Life Science Products. Reactions were incubated at $68^{\circ} \mathrm{C}$ for $30 \mathrm{~min}$, rinsed twice with TE buffer, and unincorporated fluorescent ddNTPs were removed by electrophoresis of the beads at $100 \mathrm{~V}$ for $1 \mathrm{~h}$. Individual beads were separated (if the solid-phase amplification reaction had been multiplexed) and equilibrated into $1 \times$ NEBuffer 2 , and digested overnight at $37^{\circ} \mathrm{C}$ with $40 \mathrm{U} P v u \mathrm{II}$ enzyme. Reaction supernatants were precipitated with $\mathrm{NaOAc} / \mathrm{EtOH}$ and resuspended in $10 \mu \mathrm{L}$ TE buffer. Aliquots were mixed with an equal volume of loading solution (5:1 deionized Formamide: 50 $\mathrm{mM}$ EDTA), heated at $90^{\circ} \mathrm{C}$ for 2 min followed by an ice quench, and run on 6\% acrylamide (19:1 acrylamide: bisacrylamide), $8.3 \mathrm{M}$ urea, $1 \times$ TBE gels on an ABI $373 \mathrm{DNA}$ Sequencer. Data was analyzed using the ABI 672 Genescan Collection Software (version 1.1) and Genescan PCR Analysis Software (version 1.2.2-1). The $B b v \mathrm{I}$ recognition site was placed into the forward primer in the ALAD, 5-HT $2 \mathrm{a}$ IL1B, DRD5, and CACNLG amplicons resulting in fluorescent labeling of the noncoding strand such that blue electropherogram tracings indicated a $\mathrm{C}$ allele, red tracings indicated an A allele, green tracings indicated a T allele, and black (yellow) tracings indicated a $\mathrm{G}$ allele. The $B b v \mathrm{I}$ recognition site was placed into the reverse primer for the DRD2a, DRD2b, and DCP1 amplicons resulting in fluorescent labeling of the coding strand such that blue electropherogram tracings indicated a G allele, red tracings indicated a $\mathrm{T}$ allele, green tracings indicated an $\mathrm{A}$ allele, and black (yellow) tracings indicated a C allele.

\section{ACKNOWLEDGMENTS}

We thank Drs. Chris Boles, Ezra Abrams, Chris Adams, and Bill Dower for scientific discussions and Michelle Boatwright for technical assistance.

The publication costs of this article were defrayed in part by payment of page charges. This article must therefore be hereby marked "advertisement" in accordance with 18 USC section 1734 solely to indicate this fact.

\section{REFERENCES}

Adams, C. and Kron, S. 1997. Method for performing amplification of nucleic acid with two primers bound to a single solid support. US Patent No. 5641658.

Alderborn, A., Kristofferson, A., and Hammerling, U. 2000.

Determination of single-nucleotide polymorphisms by real-time pyrophosphate DNA sequencing. Genome Res. 10: 1249-1258.
Astrin, K.H., Kaya, A.H., Wetmur, J.G., and Desnick, R.J. 1991. RsaI polymorphism in the human delta-aminolevulinate dehydratase gene at 9q34. Nucleic Acids Res. 19: 4307.

Brenner, S., Johnson, M., Bridgham, J., Golda, G., Lloyd, D.H., Johnson, D., Luo, S., McCurdy, S., Foy, M., Ewan, M., et al. 2000. Gene expression analysis by massively parallel signature sequencing (MPSS) on microbead arrays. Nat. Biotechnol. 18: $630-634$.

Broude, N.E., Zhang, L., Woodward, K., Englert, D., and Cantor, C.R. 2001. Multiplex allele-specific target amplification based on PCR suppression. Proc. Natl. Acad. Sci. 98: 206-211.

Cai, H., White, P.S., Torney, D., Deshpande, A., Wang, Z., Marrone, B., and Nolan, J.P. 2000. Flow cytometry-based minisequencing: A new platform for high-throughput single-nucleotide polymorphism scoring. Genomics 66: 135-143.

Chelly, J., Kaplan, J.C., Maire, P., Gautron, S., and Kahn, A. 1988 Transcription of the dystrophin gene in human muscle and non-muscle tissue. Nature 333: 858-860.

Chen, J., Iannone, M.A., Li, M.S., Taylor, J.D., Rivers, P., Nelsen, A.J., Slentz-Kesler, K.A., Roses, A., and Weiner, M.P. 2000. A microsphere-based assay for multiplexed single nucleotide polymorphism analysis using single base chain extension. Genome Res. 10: 549-557.

Choi, Y.W., Kotzin, B., Herron, L., Callahan, J., Marrack, P., and Kappler, J. 1989. Interaction of Staphylococcus aureus toxin "superantigens" with human T cells. Proc. Natl. Acad. Sci. 86: $8941-8945$

di Giovine, F.S., Takhsh, E., Blakemore, A.I., and Duff, G.W. 1992. Single base polymorphism at -511 in the human interleukin-1 beta gene (IL1 beta). Hum. Mol. Genet. 1: 450.

Edwards, M.C. and Gibbs, R.A. 1994. Multiplex PCR: Advantages, development, and applications. PCR Methods Appl. 3: S65-S75.

Fan, J.B., Chen, X., Halushka, M.K., Berno, A., Huang, X., Ryder, T., Lipshutz, R.J., Lockhart, D.J., and Chakravarti, A. 2000. Parallel genotyping of human SNPs using generic high-density oligonucleotide tag arrays. Genome Res. 10: 853-860.

Gray, I.C., Campbell, D.A., and Spurr, N.K. 2000. Single nucleotide polymorphisms as tools in human genetics. Hum. Mol. Genet. 9: 2403-2408.

Grossman, P.D., Bloch, W., Brinson, E., Chang, C.C., Eggerding, F.A., Fung, S., Iovannisci, D.M., Woo, S., Winn-Deen, E.S., and Iovannisci, D.A. 1994. High-density multiplex detection of nucleic acid sequences: Oligonucleotide ligation assay and sequence-coded separation. Nucleic Acids Res. 22: 45274534.

Hall, J.G., Eis, P.S., Law, S.M., Reynaldo, L.P., Prudent, J.R., Marshall, D.J., Allawi, H.T., Mast, A.L., Dahlberg, J.E., Kwiatkowski, R.W., et al. 2000. Sensitive detection of DNA polymorphisms by the serial invasive signal amplification reaction. Proc. Natl. Acad. Sci. 97: 8272-8277.

Hauge, X.Y., Grandy, D.K., Eubanks, J.H., Evans, G.A., Civelli, O., and Litt, M. 1991. Detection and characterization of additional DNA polymorphisms in the dopamine D2 receptor gene. Genomics 10: 527-530.

Iannone, M.A., Taylor, J.D., Chen, J., Li, M.S., Rivers, P., Slentz-Kesler, K.A., and Weiner, M.P. 2000. Multiplexed single nucleotide polymorphism genotyping by oligonucleotide ligation and flow cytometry. Cytometry 39: 131-140.

Kan, Y.W. and Dozy, A.M. 1978. Polymorphism of DNA sequence adjacent to human $\beta$-globin structural gene: Relationship to sickle mutation. Proc. Natl. Acad. Sci. 75: 5631-5635.

Krook, A., Stratton, I.M., and O'Rahilly, S. 1992. Rapid and simultaneous detection of multiple mutations by pooled and multiplex single nucleotide primer extension: application to the study of insulin-responsive glucose transporter and insulin receptor mutations in non-insulin-dependent diabetes. Hum. Mol. Genet. 1: 391-395.

Kruglyak, L. 1999. Prospects for whole-genome linkage disequilibrium mapping of common disease genes. Nat. Genet. 22: $139-144$.

Laken, S.J., Jackson, P.E., Kinzler, K.W., Vogelstein, B., Strickland, P.T., Groopman, J.D., and Friesen, M.D. 1998. Genotyping by mass spectrometric analysis of short DNA fragments. Nat. Biotechnol. 16: 1352-1356.

Landegren, U., Nilsson, M., and Kwok, P.Y. 1998. Reading bits of genetic information: Methods for single-nucleotide polymorphism analysis. Genome Res. 8: 769-776.

Liu, Q., Thorland, E.C., Heit, J.A., and Sommer, S.S. 1997. Overlapping PCR for bidirectional PCR amplification of specific alleles: A rapid one-tube method for simultaneously 
differentiating homozygotes and heterozygotes. Genome Res. 7: 389-398.

Livak, K.J. 1999. Allelic discrimination using fluorogenic probes and the 5' nuclease assay. Genet. Anal. 14: 143-149.

Lizardi, P.M., Huang, X., Zhu, Z., Bray-Ward, P., Thomas, D.C., and Ward, D.C. 1998. Mutation detection and single-molecule counting using isothermal rolling-circle amplification. Nat. Genet. 19: 225-232.

Mitra, R.D. and Church, G.M. 1999. In situ localized amplification and contact replication of many individual DNA molecules. Nucleic Acids Res. 27: e34.

Olckers, A., Jedlicka, A.E., Powers, P.A., Hogan, K., Gregg, R.G., and Levitt, R.C. 1993. G to A polymorphism in the CACNLG gene. Hum. Mol. Genet. 2: 2198.

Pastinen, T., Kurg, A., Metspalu, A., Peltonen, L., and Syvanen, A.C. 1997. Minisequencing: A specific tool for DNA analysis and diagnostics on oligonucleotide arrays. Genome Res. 7: 606-614.

Pastinen, T., Partanen, J., and Syvanen, A.C. 1996. Multiplex, fluorescent, solid-phase minisequencing for efficient screening of DNA sequence variation. Clin. Chem. 42: 1391-7.

Rehman, F.N., Audeh, M., Abrams, E.S., Hammond, P.W., Kenney, M., and Boles, T.C. 1999. Immobilization of acrylamide-modified oligonucleotides by co-polymerization. Nucleic Acids Res. 27: 649-655.

Rieder, M.J., Taylor, S.L., Clark, A.G., and Nickerson, D.A. 1999. Sequence variation in the human angiotensin converting enzyme. Nat. Genet. 22: 59-62.

Risch, N. and Merikangas, K. 1996. The future of genetic studies of complex human diseases. Science 273: 1516-1517.

Sachidanandam, R., Weissman, D., Schmidt, S.C., Kakol, J.M., Stein, L.D., Marth, G., Sherry, S., Mullikin, J.C., Mortimore, B.J., Willey, D.L., et al. 2001. A map of human genome sequence variation containing 1.42 million single nucleotide polymorphisms. Nature 409: 928-933.
Schork, N.J., Fallin, D., and Lanchbury, J.S. 2000. Single nucleotide polymorphisms and the future of genetic epidemiology. Clin. Genet. 58: 250-264.

Shi, M.M. 2001. Enabling large-scale pharmacogenetic studies by high-throughput mutation detection and genotyping technologies. Clin. Chem. 47: 164-172.

Sommer, S.S., Sobell, J.L., and Heston, L.L. 1993. A common exonic polymorphism in the human D5 dopamine receptor gene. Hum. Genet. 92: 633-634.

Steemers, F.J., Ferguson, J.A., and Walt, D.R. 2000. Screening unlabeled DNA targets with randomly ordered fiber-optic gene arrays. Nat. Biotechnol. 18: 91-94.

Velculescu, V.E., Zhang, L., Vogelstein, B., and Kinzler, K.W. 1995. Serial analysis of gene expression. Science 270: $484-487$.

Wang, D.G., Fan, J.B., Siao, C.J., Berno, A., Young, P., Sapolsky, R., Ghandour, G., Perkins, N., Winchester, E., Spencer, J., et al. 1998. Large-scale identification, mapping, and genotyping of single-nucleotide polymorphisms in the human genome. Science 280: $1077-1082$.

Warren, J.T., Peacock, M.L., Rodriguez, L.C., and Fink, J.K. 1993. An MspI polymorphism in the human serotonin receptor gene (HTR2): Detection by DGGE and RFLP analysis. Hum. Mol. Genet. 2: 338 .

Westin, L., Xu, X., Miller, C., Wang, L., Edman, C.F., and Nerenberg, M. 2000. Anchored multiplex amplification on a microelectronic chip array. Nat. Biotechnol. 18: 199-204.

Wiesner, R.J. 1992. Direct quantification of picomolar concentrations of mRNAs by mathematical analysis of a reverse transcription/exponential polymerase chain reaction assay. Nucleic Acids Res. 20: 5863-5864.

Received July 12, 2001; accepted in revised form August 24, 2001.

\section{Genome Research}




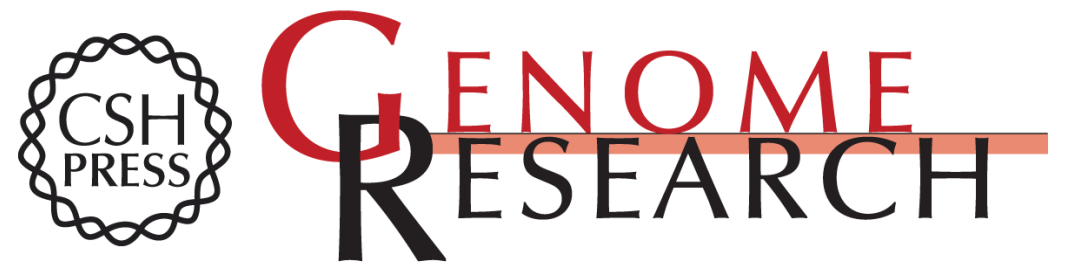

\section{SNP Genotyping by Multiplexed Solid-Phase Amplification and Fluorescent Minisequencing}

Michael H. Shapero, Kerstin K. Leuther, Anhthu Nguyen, et al.

Genome Res. 2001 11: 1926-1934

Access the most recent version at doi:10.1101/gr.205001

\section{License}

Email Alerting Service

Receive free email alerts when new articles cite this article - sign up in the box at the top right corner of the article or click here.

\section{Affordable, Accurate} Sequencing.

To subscribe to Genome Research go to: https://genome.cshlp.org/subscriptions 